\title{
Disparities in Oral Health among School-Aged Children in Kansas
}

\author{
Frank Dong1 ${ }^{*}$, Elizabeth Ablah1, Robert Hines' ${ }^{1}$, Ann Lazar ${ }^{2}$, Judy Johnston ${ }^{1}$ \\ ${ }^{1}$ Department of Preventive Medicine \& Public Health, University of Kansas School of Medicine, Wichita, USA \\ ${ }^{2}$ University of California, School of Dentistry, San Francisco, CA, USA \\ Email: fdong@kumc.edu, eablah@kumc.edu, rhines@kumc.edu, ann.lazar@ucsf.edu, jjohnsto@kumc.edu
}

Received 8 January 2015; accepted 27 June 2015; published 30 June 2015

Copyright (C) 2015 by authors and Scientific Research Publishing Inc.

This work is licensed under the Creative Commons Attribution International License (CC BY).

http://creativecommons.org/licenses/by/4.0/

(c) (i) Open Access

\begin{abstract}
Background: The effects of age, rural-urban geographic location, and percentage of Free and Reduced Price Meal Program (FRPMP) participation on children's oral health outcome measures (untreated decay, treated decay, and sealants) have not been fully explored in Kansas. Methods: The current study utilized a surveillance sample of 140,217 children (grades K through 12) attending 200 schools in Kansas, which requested screening assistance from the Kansas Department of Health and Environment (KDHE) from 2012 to 2013. Multilevel logistic regression analysis was conducted to identify significant factors associated with oral health outcome measures. Results: Older children were associated with decreased odds of having untreated decay, and increased odds of having treated decay and sealants. Children attending very rural schools had increased odds of untreated and treated decay and decreased odds of presence of sealants. For every $5 \%$ increase in the school-level \%FRPMP, the odds of having untreated and treated decay increased by $5 \%$ and $3 \%$, respectively. However, \%FRPMP was not statistically associated with the presence of sealants. Conclusions: Children attending schools in very rural and rural areas appear to have worse oral health outcomes, as measured by higher proportions of untreated and treated decay, and a smaller proportion of presence of sealants.
\end{abstract}

\section{Keywords}

Untreated Decay, Treated Decay, Sealants, School Children, Rural, Age

\section{Introduction}

Although oral health status among Americans has been generally improved over time, dental decay in primary

*Corresponding author.

How to cite this paper: Dong, F., Ablah, E., Hines, R., Lazar, A. and Johnston, J. (2015) Disparities in Oral Health among School-Aged Children in Kansas. Open Journal of Preventive Medicine, 5, 291-298.

http://dx.doi.org/10.4236/ojpm.2015.56032 
teeth has increased in American children aged 2 to 5 years [1]. More than half (51.2\%) of children aged 6 to 11 years have decay in their primary teeth, and among them, $24.5 \%$ have untreated decay [2]. In fact, almost one-third of school-aged children in the United States have untreated dental decay [3]. Tooth decay can impact these children in multi-factorial ways, including causing pain and tooth loss [4], affecting their overall health [5], and limiting their ability to eat, sleep, and learn [6]. Healthy People 2020 includes a goal of decreasing untreated dental decay among children, specifically among those who are 3 to 5 years (from 23.8\% to 21.4\%), 6 to 9 years (from $28.8 \%$ to $25.9 \%$ ), and 13 to 15 years (from $17 \%$ to $15.3 \%$ ) [7].

Sealants are an effective and economical measure to prevent or halt progression of tooth decay [8]-[11]. Sealing the occlusal surfaces of permanent molars of children and adolescents prevents the development of caries and avoids future invasive treatment [8] [11]. Accordingly, Healthy People 2020 includes an objective to increase the proportion of children and adolescents who have received dental sealants on their permanent posterior teeth [12]. To achieve this objective, a school-based sealant program can help to decrease or eliminate barriers to preventive dental service among school-aged children [13].

Several risk factors associated with children's untreated decay have been identified in the literature including older age, rural residence, and poverty. The results of studies that have investigated the association of age and geographic location with having untreated tooth decay are inconclusive [4] [14]-[17]. Weyant et al. explored the prevalence of oral health status among school children in grades $1,3,9$, and 11 . They reported a decreasing trend in untreated tooth decay as youth got older [15]. Residents of rural areas have been reported to have more untreated decay than their urban and suburban counterparts [4] [14] [16]. However, Alonge and Narandran reported a higher prevalence of decay among school children in urban populations relative to rural populations in a foreign country setting [17].

Additionally, two studies suggested that children attending schools with greater than $50 \%$ Free and Reduced Price Meal Program (FRPMP) participation have the greatest frequency of untreated tooth decay [18] [19]. However, one of these two studies used only kindergarteners as their sample [18], and the other study surveyed only third-grade students [19]. Surveying one particular age group precludes the ability to assess trends with increasing grades, and it limits the generalizability of findings to other grades. As such, there is a critical need to assess the effect of FRPMP across all grades in school children.

To date, few researches have been conducted using statewide surveillance data to identify the effects of age, rural-urban geographic location, and the percentage of children receiving FRPMP on untreated decay, treated decay, and the presence of sealants among children from grades K through 12 . This study will identify populations that are more likely to have untreated decay, treated decay, and sealants. The findings in this study may be useful to inform health professionals, school administrators, and policy makers to develop interventions targeting school-aged children.

\section{Methods}

\subsection{Participants}

This study used data from a convenience sample of 140,217 children attending 200 schools from 105 counties in Kansas from 2012 to 2013. To participate in the School Sealants Program, schools may request screening assistance from the Bureau of Oral Health (BOH) at Kansas Department of Health and Environment (KDHE). The School Sealant Program in Kansas generally targets low-income schools, and services are provided by 17 safetynet clinics, volunteer dental clinics, volunteer hygienists, and dental/dental-hygiene students supervised by licensed dental professionals.

School-aged children, grades $\mathrm{K}$ through 12 , were screened by trained dental professionals and dental-hygiene students with supervision by licensed dental professionals. Newsletter articles from the BOH informed school nurses that this screening is mandated by law and offered them the option of requesting help from the $\mathrm{BOH}$ at KDHE. The BOH staff also presented this information at school nurse conferences. Training for licensed dental professionals to participate in the screening program was completed online and included a post-test demonstration of skills. Dental hygiene students received in-person training in screening techniques and data entry by specifically trained licensed dental professionals. All screeners were required to pass the training to standardize the quality of screenings and consistency of data entry. Successful completion of the training resulted in issuance of a password that allowed dental professionals to complete data entry following screening. Following each school screening, screeners submitted aggregated, classroom-level data to the BOH at KDHE. 


\subsection{Instruments}

The screening form captured data such as school district number, school name, date of screening, student grade level, and child's name. The trained dental professionals recorded their evaluation of each child's oral health status, including untreated decay status (yes vs. no), treated decay status (yes vs. no), and sealants status (yes vs. no). No distinction was made on the severity of children's oral health issues between single versus multiple occurrences of treated or untreated decay. Screeners also assessed treatment needs and categorized the children as having no decay/problems, needing sealants, needing a dentist's examination, and needing urgent care. Dentist and dental hygienists also had opportunities to leave additional comments on the screening form regarding the child's teeth.

\subsection{Procedure}

Each classroom was screened as one unit by a dental professional. The screeners aggregated the data by children's grade and reported the total number of students having untreated decay, treated decay, and the presence of sealants along with treatment needs. The data were reported back to KDHE by grade level. No individual data were reported. School nurses assumed the responsibility of documenting the information in each student's individual health record and sending notifications of the child's oral health screenings results to parents/guardians. Efforts are made by the school nurses to assist parents/guardians with referral completion. KDHE provides suggestions of dentists or dental services where parents can send their child for treatment.

The county corresponding to each school district was mapped by the research team and was subsequently classified into three geographic categories using Rural-Urban Continuum Codes (RUCC) [20]. RUCC are based on the population size of metro areas and non-metropolitan counties by degree of urbanization and adjacency to a metro area. RUCC have nine levels ranging from 1 (metro) to 9 (completely rural). We used the following classification scheme to classify school districts according to geographic area: RUCC 1 - 3 were urban, 4 - 6 were rural, and 7 - 9 were very rural. Similar classification scheme was used in other studies [21] [22]. The percentage of free and reduced lunch information was obtained through the Kansas State Department of Education (KSDE) database [23]. Dental screening data and KSDE data were linked based on the school and county name to cross-validate the match.

\subsection{Data Analysis}

All statistical analyses were conducted using SAS software for Windows (version 9.3, Cary, North Carolina). Descriptive statistics were presented as frequencies and percentages for categorical variables. Chi-square analyses were conducted to evaluate the association between rurality, grade, and professional evaluation of multiple measures of school children's teeth. A multilevel logistic regression analysis was conducted to identify the effect of rurality, grade, and the school-level percentage of free and reduced lunch participation on oral health status. The school district was considered as the second level, and the aggregated information for each grade was considered as the first level. The interaction effect of rurality and grade was evaluated to decide whether the interaction term should be included in the regression analysis. The degree of freedom was determined by the Satterthwaite method for the multi-level model. The intra-class correlation was computed to confirm the validity of multi-level regression. All statistical tests were two-sided. P-value $<0.05$ was considered to be statistically significant.

\section{Results}

A total of 140,217 children attending 200 schools from 105 counties in Kansas were included in the analysis. Two-thirds (67.5\%) of the sample were enrolled in grades $\mathrm{K}$ through 5, and 51.6\% of the sample resided in rural or very rural geographical locations (Table 1). Eighteen percent (17.7\%) of the sample had untreated decay, $39.8 \%$ had treated decay, and $30.7 \%$ had sealants.

School children were evaluated on the presence of untreated decay (yes or no), treated decay (yes or no), and presence of sealants (yes or no). Chi-square analysis was conducted to assess the three outcome measures by the grade and geographic locations (urban, rural, vs. very rural). The bivariate analysis results are presented in Table 2. Younger children were more likely to have untreated decay and less likely to have sealants than older children. However, no such grade pattern was evident regarding treated decay. Similarly, children who attended 
Table 1. Participants’ demographic information.

\begin{tabular}{|c|c|c|}
\hline Grade & Frequency $(\mathrm{N}=140,217)$ & Percent \\
\hline Grade K through 2 & 48,324 & 34.5 \\
\hline Grade 3 through 5 & 46,273 & 33.0 \\
\hline Grade 6 through 8 & 31,530 & 22.5 \\
\hline Grade 9 through 12 & 14,090 & 10.0 \\
\hline \multicolumn{3}{|l|}{ Geography } \\
\hline Very Rural & 29,715 & 21.2 \\
\hline Rural & 42,595 & 30.4 \\
\hline Urban & 67,907 & 48.4 \\
\hline \multicolumn{3}{|l|}{ Untreated Decay } \\
\hline Yes & 24,744 & 17.7 \\
\hline No & 115,473 & 82.3 \\
\hline \multicolumn{3}{|l|}{ Treated Decay } \\
\hline Yes & 55,839 & 39.8 \\
\hline No & 84,378 & 60.2 \\
\hline \multicolumn{3}{|l|}{ Sealants } \\
\hline Yes & 42,995 & 30.7 \\
\hline No & 97,222 & 69.3 \\
\hline
\end{tabular}

Table 2. Bivariate analysis of grade and geographic location vs. dental status for school students ${ }^{\mathrm{a}}$.

\begin{tabular}{|c|c|c|c|c|c|c|c|c|c|}
\hline \multirow[b]{2}{*}{ Grade } & \multicolumn{2}{|c|}{ Untreated Decay } & \multirow{2}{*}{$\begin{array}{c}\mathrm{p} \\
<0.01\end{array}$} & \multicolumn{2}{|c|}{ Treated Decay } & \multirow{2}{*}{$\begin{array}{c}\mathrm{p} \\
<0.01\end{array}$} & \multicolumn{2}{|c|}{ Sealants } & \multirow{2}{*}{$\begin{array}{c}\mathrm{p} \\
<0.01\end{array}$} \\
\hline & No & Yes & & No & Yes & & No & Yes & \\
\hline K through 2 & 38,541 (79.8) & $9783(20.2)$ & & $31,623(65.4)$ & $16,701(34.6)$ & & $\mathrm{N} / \mathrm{A}^{\mathrm{b}}$ & $\mathrm{N} / \mathrm{A}^{\mathrm{b}}$ & \\
\hline 3 through 5 & $37,571(81.2)$ & 8702 (18.8) & & $25,420(54.9)$ & $20,853(45.1)$ & & 29,145 (63.0) & $24,484(37.0)$ & \\
\hline 6 through 8 & 27,338 (86.7) & 4192 (13.3) & & $19,568(62.1)$ & 11,962 (37.9) & & $18,521(58.7)$ & 13,009 (41.3) & \\
\hline 9 through 12 & 12,023 (85.3) & 2067 (14.7) & & 7767 (55.1) & 6323 (44.9) & & 8588 (61.0) & 5502 (39) & \\
\hline Rurality & & & $<0.01$ & & & $<0.01$ & & & $<0.01$ \\
\hline Very Rural & $23,821(80.2)$ & 5894 (19.8) & & $15,971(53.7)$ & $13,744(46.3)$ & & 22,689 (76.4) & 7026 (23.6) & \\
\hline Rural & $34,262(80.4)$ & 8333 (19.6) & & 26,829 (63) & 15,766 (37) & & 30,187 (70.9) & $12,408(29.1)$ & \\
\hline Urban & $57,390(84.5)$ & 10,517 (15.5) & & $41,578(61.2)$ & 26,329 (38.8) & & $44,346(65.3)$ & $23,561(34.7)$ & \\
\hline
\end{tabular}

${ }^{\mathrm{a}}$ All numbers are presented as $\mathrm{n}(\%)$. ${ }^{\mathrm{b}}$ Grades $\mathrm{K}$ through 2 was excluded from the analysis on sealants. Children in Grades $\mathrm{K}$ through 2 do not typically have permanent teeth, which would require sealants when they have teeth issues.

schools located in very rural areas had worse oral health outcome measures than their urban counterparts, as measured by having greater proportions of untreated decay (19.8\%), greater proportions of treated decay (46.3\%) and smaller proportions of sealants (23.6\%). The associations between the three outcome measures and grade and geographic location were statistically significant (P-value $<0.01$ for all six comparisons, Table 2).

Multilevel logistic regression analysis was conducted to assess the effect of grade, geographic locations and \%FRPMP on the three outcome measures: untreated decay, treated decay, and presence of sealants. These results are presented in Table 3.

\subsection{Untreated Decay}

As the students' grade level increased, the odds ratio (OR) of having untreated tooth decay decreased (OR = 
Table 3. Odds Ratio Estimates of having untreated tooth decay with 95\% confidence interval.

\begin{tabular}{|c|c|c|c|c|c|c|}
\hline & \multicolumn{2}{|c|}{ Untreated decay } & \multicolumn{2}{|c|}{ Treated decay } & \multicolumn{2}{|c|}{ Sealants } \\
\hline & Partially adjusted ${ }^{a}$ & Fully adjusted $^{\mathrm{b}}$ & $\begin{array}{l}\text { Partially } \\
\text { adjusted }^{\text {a }}\end{array}$ & Fully adjusted $^{\mathrm{b}}$ & $\begin{array}{l}\text { Partially } \\
\text { adjusted }^{\mathrm{a}}\end{array}$ & Fully adjusted $^{\mathrm{b}}$ \\
\hline \multicolumn{7}{|l|}{ Grade } \\
\hline K through 2 & Reference & Reference & Reference & Reference & Not Applicable ${ }^{\mathrm{d}}$ & Not Applicable $\mathrm{d}^{\mathrm{d}}$ \\
\hline 3 through 5 & $0.93(0.90,0.96)$ & $0.93(0.90,0.97)$ & $1.61(1.56,1.65)$ & $1.60(1.56,1.65)$ & Reference & Reference \\
\hline 6 through 8 & $0.61(0.58,0.63)$ & $0.62(0.60,0.65)$ & $1.20(1.16,1.24)$ & $1.21(1.17,1.25)$ & $1.17(1.13,1.21)$ & $1.16(1.12,1.20)$ \\
\hline 9 through 12 & $0.62(0.59,0.66)$ & $0.69(0.65,0.73)$ & $1.79(1.71,1.87)$ & $1.91(1.82,2.0)$ & $1.27(1.21,1.33)$ & $1.29(1.22,1.35)$ \\
\hline \multicolumn{7}{|l|}{ Geography } \\
\hline Very Rural & $1.49(1.26,1.77)$ & $1.31(1.10,1.56)$ & $1.53(1.29,1.81)$ & $1.40(1.15,1.70)$ & $0.65(0.55,0.78)$ & $0.50(0.42,0.60)$ \\
\hline Rural & $1.45(1.22,1.71)$ & $1.21(0.99,1.46)$ & $1.26(1.09,1.45)$ & $0.97(0.78,1.21)$ & $0.82(0.70,0.96)$ & $0.93(0.77,1.12)$ \\
\hline Urban & Reference & Reference & Reference & Reference & Reference & Reference \\
\hline \%FRPMP ${ }^{c}$ & & $1.05(1.05,1.06)$ & & $1.03(1.03,1.04)$ & & $1.00(1.00,1.00)$ \\
\hline
\end{tabular}

${ }^{a}$ partially adjusted for geography and grade, badjusted for geography, grade and percentage of free/reduced lunch, 'the odds ratio estimate was based on 5\% increment in \%FRPMP (Free and Reduced Price Meal Program), ${ }^{\mathrm{d}}$ Grade K through 2 was excluded from the analysis on sealants. Children in Grades K through 2 do not typically have permanent teeth, which would not require sealants when they have teeth issues.

0.93, 0.62, and 0.69 for graded 3 through 5, graded 6 through 8 , and graded 9 through 12, respectively). Compared to children from urban areas, children from very rural areas had $31 \%$ increased odds $(\mathrm{OR}=1.31,95 \% \mathrm{CI}$ $1.10,1.56)$ of having untreated decay. Students from rural areas had a $21 \%$ increased odds (OR $=1.21,95 \%$ CI $0.99,1.46)$ of having untreated decay although this result failed to reach statistical significance. Finally, for every five percent increase in the school-level FRPMP participation, the odds of having untreated decay increased by $5 \%(\mathrm{OR}=1.05,95 \% \mathrm{CI} 1.05,1.06)$.

\subsection{Treated Decay}

Compared to children in grades $\mathrm{K}$ through 2 , as the students' grade level increased, the odds of having treated decay also increased $(\mathrm{OR}=1.61,1.20$, and 1.79 for grades 3 through 5 , grades 6 through 8 , and grades 9 through 12, respectively). For the geographic effect, children from very rural areas had the highest odds of having treated decay $(\mathrm{OR}=1.40,95 \% \mathrm{CI} 1.15,1.70)$ as compared to their urban counterparts. However, there was no statistically significant difference on the proportions of treated decay between rural and urban areas $(\mathrm{OR}=$ 0.97, 95\% CI 0.78, 1.21). For every five percent increase in the school-level FRPMP participation, the relative odds of having treated decay increased by $3 \%(\mathrm{OR}=1.03,95 \%$ CI $1.03,1.04)$.

\subsection{Presence of Sealants}

As the students' grade level increased, the odds of having sealants also increased (OR = 1.16 and 1.29 for grades 6 through 8, and grades 9 through 12, respectively). Compared to children from urban areas, students from very rural areas had $50 \%$ decreased odds of having sealants ( $\mathrm{OR}=0.50,95 \% \mathrm{CI} 0.42,0.60)$. There is no statistically significant difference between rural and urban areas (OR $=0.93,95 \%$ CI $0.77,1.12)$. The percentage of schoollevel participation in free and reduced lunch program was not associated with sealant status.

\section{Discussion}

Previous research has reported that age, geographic locations, and \%FRPMP were associated with oral health outcomes [4] [5] [7] [14]-[19], as measured by untreated decay, treated decay, and presence of sealants. The current study found that older children were associated with better oral health outcome measures, while rural and very rural geographic locations and higher \%FRPMP were associated with worse oral health outcome measures.

The current study found that older age was associated with decreased odds of having untreated decay, and in- 
creased odds of having treated decay and sealants after adjusting for geographic locations (very rural, rural and urban) and \%FRPMP. Similar findings were reported by Weyant et al., where a decreasing trend of having untreated decay was observed as the grade increased among school-aged children based on a random sample of children in grades 1, 3, 9 and 11 [15]. However, conflicting results were reported by Dawkins et al., who found a higher proportion of untreated decay in older children [14]. This difference might be attributed to different study settings. Dawkins et al. collected data from a school-based dental sealant program using a mobile dental unit in a medically-underserved region of Kentucky. Their study included children ages six to 15 years, primarily focusing on second and seventh grade students (ages 7 and 12). Study participants included only first-time patients of the mobile dental unit. The current study is based on an annual surveillance screening program, which includes a statewide sample of school-aged children from grade K through 12 (ages 5 through 18). The annual screening and referral program described in the current study significantly increases the chance of identifying oral health problems at an early stage, thus reducing the chance of long-term untreated decay.

Our study suggests that compared to urban school-aged children, those from very rural areas had increased odds of having untreated and treated decay, and decreased odds of receiving sealants. Sealants are effective and economical preventive measures for dental decay [8]-[11]. By having a decreased prevalence of sealants, children from very rural areas are in a disadvantaged position by having less access to this preventive care. Our findings regarding the effect of very rural areas are consistent with those reported by other researchers [4] [14] [17].

As compared to urban geographic locations, the partially adjusted odds ratios for rural areas before including \%FRPMP in the model were 1.45 (95\% CI 1.22, 1.71), 1.26 (95\% CI 1.09, 1.45) and 0.82 (95\% CI 0.70, 0.96 ) for untreated decay, treated decay and sealants, respectively. However, there were no statistically significant differences on the oral health outcome measures between rural and urban geographic locations after factoring \%FRPMP into the statistical model. The percentage of FRPMP participation can be used as a proxy to reflect the socioeconomic status (SES) of families attending schools in the community. Namely, when the \%FRPMP was factored into the model, the rural versus urban disparity was attenuated. This indicates that SES differences (as measured by FRPMP participation) between rural and urban areas are explaining a portion of the disparity by geographic residence. Therefore, efforts to address this disparity must be focused on lower SES rural/very rural populations which represent an underserved segment of the population with a greater oral health morbidity burden. Despite the lack of statistically significant difference on oral health outcome measures between rural and urban areas, rural areas have been reported to be associated with a lack of preventive dental visits [24] and less frequent tooth brushing [25], which would support the worse oral health outcome measures in the current study. Additionally, rural children are more likely to be uninsured than urban children, and children without dental insurance are less likely to receive preventive dental care and more likely to have unmet needs for care [26].

The current study suggests that children attending schools with greater \%FRPMP were more likely to have untreated and treated decay, but \%FRPMP was not associated with the presence of sealants. Chung et al. reported similar results in that the greatest tooth decay prevalence occurred among kindergarteners attending schools with higher \%FRPMP [18]. Considering that school-based sealant programs are effective in reaching high-risk children [19], the current study assists in identifying these vulnerable populations who are not receiving adequate preventive care.

This study had several limitations. Firstly, this study used a convenience sample of schools who requested oral health screening assistance from KDHE, which could potentially bias the results. However, since Kansas is a rural state with 89 of the 105 counties being rural, the current study's findings are generalizable to other schools in Kansas who did not participate in the School Sealants Program. Secondly, the collection tool did not assess the severity of oral health conditions based on the number of teeth with untreated or treated decay, or the number of sealants in place for each child. Instead, the data collection tool categorized each condition into a dichotomous variable (yes vs. no). Although the dichotomous response on oral health is informative, the quantity of teeth with problems may be of interest to researchers and clinicians. However, no matter the number of teeth having problems, it is still recommended to seek preventive or restorative professional dental care services. Therefore, the current research still bears scientific and practical value by exploring factors associated with oral health. Lastly, to maximize the protection of children's privacy, no children identifiers or parental information was collected. This precludes the ability to explore other possible factors, such as gender, race, insurance status, and dietary habits which can also play a significant role in oral health [3] [14] [27] [28]. Nonetheless, our study has identified groups of underserved children for three important oral health outcome measures. 


\section{Conclusion}

This study provides a snapshot of oral health conditions among school-aged children (grades K through 12) in Kansas. As children become older, the odds of having untreated decay decreases, whereas the odds of having treated decay and sealants increases. School-aged children from very rural and rural areas have more untreated decay and very rural children have decreased prevalence of sealants, although the difference between rural and urban areas failed to reach statistical significance after factoring \%FRPMP into the statistical model. Additionally, children from schools with higher \%FRPMP (in rural and urban schools) had increased odds of having untreated decay. Though tooth decay is preventable, this study still suggests up to $20 \%$ of school children have untreated decay, up to $46 \%$ have treated decay, and less than one third (31\%) of school-aged children have sealants. School nurses assumed the responsibility of sending the oral health screening results to parents/guardians and made efforts with referral completion. Future research may focus on assessing the timeliness of referral completion to improve the oral health status among younger children, those in very rural/rural schools, and schools that have larger percentages of free or reduced lunch program participants.

\section{Human Subjects Approval Statement}

This study was deemed to be non-human subjects' research by the Human Subjects Committee at the University of Kansas School of Medicine-Wichita.

\section{References}

[1] Dye, B.A., Tan, S., Smith, V., et al. (2007) Trends in Oral Health Status: United States, 1988-1994 and $1999-2004$. National Center for Health Statistics. Vital and Health Statistics, Series 11, No. 248, 1-92.

[2] National Institute of Dental and Craniofacial Research (2014) Dental Caries (Tooth Decay) in Children (Age 2 to 11). http://www.nidcr.nih.gov/DataStatistics/FindDataByTopic/DentalCaries/DentalCariesChildren2to11.htm

[3] Kandel, E.A., Richards, J.M. and Binkley, C.J. (2012) Childhood Caries in the State of Kentucky, USA: A Cross-Sectional Study. BMC Oral Health, 12, 38. http://dx.doi.org/10.1186/1472-6831-12-38

[4] Vargas, C.M., Monajemy, N., Khurana, P. and Tinanoff, N. (2002) Oral Health Status of Preschool Children Attending Head Start in Maryland, 2000. Pediatric Dentistry, 24, 257-263.

[5] Miller, F.Y. (2005) The Utilization of Dental Hygiene Students in School-Based Dental Sealant Programs. Journal of Dental Hygiene: JDH/American Dental Hygienists' Association, 79, 11.

[6] Slayton, R. (2005) Oral Health Promotion in Children and Adolescents. Compendium of Continuing Education in Dentistry, 26, 30-35.

[7] U.S. Department of Health and Human Services. Health People 2020 Oral Health. http://www.healthypeople.gov/2020/topicsobjectives2020/objectiveslist.aspx?topicId=32

[8] Ahovuo-Saloranta, A., Forss, H., Walsh, T., et al. (2013) Sealants for Preventing Dental Decay in the Permanent Teeth. The Cochrane Database of Systematic Reviews, 3, Article ID: Cd001830. http://dx.doi.org/10.1002/14651858.CD001830.pub4

[9] Yildiz, E., Dorter, C., Efes, B. and Koray, F. (2004) A Comparative Study of Two Fissure Sealants: A 2-Year Clinical Follow-Up. Journal of Oral Rehabilitation, 31, 979-984. http://dx.doi.org/10.1111/j.1365-2842.2004.01334.X

[10] Ahovuo-Saloranta, A., Hiiri, A., Nordblad, A., Worthington, H. and Makela, M. (2004) Pit and Fissure Sealants for Preventing Dental Decay in the Permanent Teeth of Children and Adolescents. The Cochrane Database of Systematic Reviews, 4, Cd001830. http://dx.doi.org/10.1002/14651858.CD001830.pub2

[11] Quinonez, R.B., Downs, S.M., Shugars, D., Christensen, J. and Vann Jr., W.F. (2005) Assessing Cost-Effectiveness of Sealant Placement in Children. Journal of Public Health Dentistry, 65, 82-89.

http://dx.doi.org/10.1111/j.1752-7325.2005.tb02791.x

[12] Yakut, N. and Sonmez, H. (2006) Resin Composite Sealant vs. Polyacid-Modified Resin Composite Applied to Post Eruptive Mature and Immature Molars: Two Year Clinical Study. The Journal of Clinical Pediatric Dentistry, 30, 215218. http://dx.doi.org/10.17796/jcpd.30.3.m4285p8388511374

[13] Devlin, D. and Henshaw, M. (2011) Improving Access to Preventive Dental Services through a School-Based Dental Sealant Program. Journal of Dental Hygiene: JDH/American Dental Hygienists’ Association, 85, 211-219.

[14] Dawkins, E., Michimi, A., Ellis-Griffith, G., Peterson, T., Carter, D. and English, G. (2013) Dental Caries among Children Visiting a Mobile Dental Clinic in South Central Kentucky: A Pooled Cross-Sectional Study. BMC Oral Health, 13, 19. http://dx.doi.org/10.1186/1472-6831-13-19 
[15] Weyant, R.J., Manz, M. and Corby, P. (2004) Dental Caries Status and Need for Dental Treatment of Pennsylvania Public School Children in Grades 1, 3, 9, and 11. Journal of Public Health Dentistry, 64, 136-144. http://dx.doi.org/10.1111/j.1752-7325.2004.tb02743.x

[16] Maserejian, N.N., Tavares, M.A., Hayes, C., Soncini, J.A. (2008) Trachtenberg FL. Rural and Urban Disparities in Caries Prevalence in Children with Unmet Dental Needs: the New England Children's Amalgam Trial. Journal of Public Health Dentistry, 68, 7-13. http://dx.doi.org/10.1111/j.1752-7325.2007.00057.x

[17] Alonge, O.K. and Narendran, S. (1999) Dental Caries Experience among School Children in St. Vincent and the Grenadines: Report of the First National Oral Health Survey. Community Dental Health, 16, 45-49.

[18] Chung, L.H., Shain, S.G., Stephen, S.M. and Weintraub, J.A. (2006) Oral Health Status of San Francisco Public School Kindergarteners 2000-2005. Journal of Public Health Dentistry, 66, 235-241. http://dx.doi.org/10.1111/j.1752-7325.2006.tb04075.x

[19] Siegal, M.D. and Detty, A.M. (2010) Targeting School-Based Dental Sealant Programs: Who Is at "Higher Risk"? Journal of Public Health Dentistry, 70, 140-147. http://dx.doi.org/10.1111/j.1752-7325.2009.00155.x

[20] United States Department of Agriculture (2013) Rural-Urban Continuum Codes. http://www.ers.usda.gov/data-products/rural-urban-continuum-codes.aspx

[21] Hauenstein, E.J., Petterson, S., Rovnyak, V., Merwin, E., Heise, B. and Wagner, D. (2007) Rurality and Mental Health Treatment. Administration and Policy in Mental Health and Mental Health Services Research, 34, 255-267. http://dx.doi.org/10.1007/s10488-006-0105-8

[22] Bopp, M. and Fallon, E.A. (2011) Individual and Institutional Influences on Faith-Based Health and Wellness Programming. Health Education Research, 26, 1107-1119.

[23] Kansas State Department of Education (2014) School Finance Publications. http://www.ksde.org/Agency/FiscalandAdministrativeServices/SchoolFinance/ReportsandPublications.aspx\#FreeandR educed

[24] Martin, A.B., Vyavaharkar, M., Veschusio, C. and Kirby, H. (2012) Rural-Urban Differences in Dental Service Utilization among an Early Childhood Population Enrolled in South Carolina Medicaid. Maternal and Child Health Journal, 16, 203-211. http://dx.doi.org/10.1007/s10995-010-0725-1

[25] Mielnik-Blaszczak, M., Krawczyk, D., Kuc, D., Zawislak, M. and Pels, E. (2006) Hygienic Habits and the Dental Condition in 12-Year-Old Children. Advances in Medical Sciences, 51, 142-144.

[26] Liu, J., Probst, J.C., Martin, A.B., Wang, J.Y. and Salinas, C.F. (2007) Disparities in Dental Insurance Coverage and Dental Care among US Children: The National Survey of Children's Health. Pediatrics, 119, S12-S21. http://dx.doi.org/10.1542/peds.2006-2089D

[27] Southward, L.H., Robertson, A., Wells-Parker, E., et al. (2006) Oral Health Status of Mississippi Delta 3- to 5-YearOlds in Child Care: An Exploratory Study of Dental Health Status and Risk Factors for Dental Disease and Treatment Needs. Journal of Public Health Dentistry, 66, 131-137. http://dx.doi.org/10.1111/j.1752-7325.2006.tb02568.x

[28] Mobley, C., Marshall, T.A., Milgrom, P. and Coldwell, S.E. (2009) The Contribution of Dietary Factors to Dental Caries and Disparities in Caries. Academic Pediatrics, 9, 410-414.

http://dx.doi.org/10.1016/j.acap.2009.09.008 